\title{
Strategic Processes @ Nike-Making and Doing Knowledge Management
}

\author{
George Stonehouse $^{1 *, \dagger}$ and Sonal Minocha ${ }^{2 \ddagger}$ \\ ${ }^{1}$ Napier University Business School, Edinburgh, Scotland, UK \\ ${ }^{2}$ Raffles University, Raffles Education Corporation, Singapore
}

This paper contrasts theory with practice through a case study of strategic processes of knowledge management $(\mathrm{KM})$ at Nike Incorporated. From its origins as a small specialist enterprise in 1972 to a multi-billion dollar global brand, the corporation has been continuously at the forefront of developments in management practice and business innovation. This case study has been compiled from interviews with senior managers and numerous secondary sources. The paper begins with a discussion of an insider perspective on the trajectory of the organization in terms of its strategic goals and decisions on markets, customers, products, services and business processes. It then goes on to explore and critique the dynamic interplay of the processes of strategizing, learning, creativity and innovation at Nike as the basis for its knowledge-based competitive advantage (CA).

The case thus represents KM as a unique combination of processes in which learning; strategy and creativity are organized and strategically embedded within a large global organization. This has implications for future theorizing in KM, which, as we illustrate in this paper, demands a more integrative approach to research and practice. One of the key lessons for practice is that span of activity, as well as strategy, will influence the relationship between strategizing, organizing and learning and this interplay determines the success (or failure) of KM. Copyright (C) 2008 John Wiley \& Sons, Ltd.

\section{INTRODUCTION}

Nonaka (1991) argues that knowledge is the only source of lasting competitive advantage (CA) in the 21st century. This paper illustrates how knowledge management $(\mathrm{KM})$ and related processes are employed in Nike Incorporated, the global market leader in the sports apparel industry (Stonehouse et al., 2003) as the basis of its competitive edge. We begin with a discussion of Nike's CAs, which

*Correspondence to: Professor George Stonehouse, Craiglockhart Campus, Edinburgh EH14 1DJ, Scotland, UK.

E-mail: g.stonehouse@napier.ac.uk

${ }^{\dagger}$ Dean.

${ }^{\ddagger}$ Dean and Associate Professor. are based on its customers and customer knowledge, design and development, supply chain management. We conclude that this configuration of strategic knowledge processes does not fully account for Nike's competitive edge as these sources of superior performance could easily become imitable and thus unsustainable if not supported by the unique ways in which Nike integrates the processes of learning, creativity and innovation which are, as yet, unparalleled by its competition. Kiraka and Manning (2005: 288) have argued that processes drive or are driven by the strategy of the organization, yet there is very little empirical work on globally successfully organizations to support this proposal. This case study thus presents a conceptualization of KM as an

Copyright (C) 2008 John Wiley \& Sons, Ltd. 
integrative phenomenon in which learning and creativity and strategy processes interact dynamically. This has implications for organizational practice and future theorizing in the discipline.

\section{NIKE'S COMPETITIVE ADVANTAGES}

Nike is widely recognized as the market leader in the sports apparel industry by virtue of its market share, profitability and global reach (Stonehouse et al., 2003). The company was launched in 1972 and Nike's name (that of the Greek goddess of victory) and the 'swoosh' have come to symbolize its success as the leading performer in the industry. By examining the knowledge that underpins Nike's exceptional performance, and the processes through which it has been created, it is possible to shed significant light upon the nature of strategic knowledge and its creation and application.

Since the birth of Nike in 1972, from its humble origins in the 1960s as Blue Ribbon Sports (BRS), the company has become the global leader of the sports apparel industry. In 1969, BRS employed 20 people and revenues from its several retail outlets amounted to the princely sum of $\$ 300000$. By 1972, the year of the launch of the Nike brand name, it had more than doubled in size to 45 employees with revenues having increased substantially to almost $\$ 2$ million. By 1979 revenues were up to $\$ 149$ million, its shoes were being sold in several countries including Canada, Asia and Australia, and its products were being manufactured in the USA, Taiwan and Korea. Nike had almost become global. In 1981, Nike International was set up to look after the company's increasing international operations, which now encompassed more than 40 countries. In the same year Nike-England became the company's first wholly owned foreign distributor. As a direct consequence of this global expansion by 1990 Nike's revenues had reached \$2 235244000 and it was directly employing some 5300 people. The global expansion of the company has continued at an unprecedented rate so that in 2006 its revenues stood at $\$ 16.33$ billion dollars with a gross profit of $\$ 7.2$ billion, employing 29000 people worldwide, and a further 650000 workers in contracted factories around the world. Nike has gone on to win numerous awards for its design including the Industrial Design Excellence award in 2005 and the company has also gone on to overturn much of its negative press in the 1990s to be recognized as one of the world's most ethical companies in 2007 by Ethisphere Magazine.

Nike's sustained global market leadership in the sports apparel industry is based upon its excep- tional knowledge of: its customers and their motivations; marketing, design and development of new products; and management of its supply chain. These knowledge domains are melded together into the unique strategic knowledge, which constitutes Nike's core competences and CA. This section of the paper details and explains the knowledge base upon which Nike's core competences draw. The subsequent section presents a detailed theoretical and critical analysis of the knowledge base and the ways in which it has been created and deployed so as to gain and sustain a significant competitive edge.

\section{Customers and customer knowledge}

In 1972, when Phil Knight and Bill Bowerman formed the company, its products were targeted at the narrow market sector of serious, competitive athletes. Of course, most serious athletes are young men and women, so that Nike's main customers were in their late teens and early 20s. The targeting of this customer group of serious athletes led Nike to focus on the development of high performance running shoes. Having been keen amateur athletes themselves, Knight and Bowerman had considerable tacit and explicit knowledge of the performance that athletes demand from their shoes. In fact, it was their personal dissatisfaction with existing athletic shoes, which led them to set up Nike to produce shoes, which were fit for purpose in terms of comfort and durability. They launched their offerings at the US Olympic track and field trials and in the mid 1970s they developed the first impact-absorbing sole drawing upon their tacit knowledge of runners' needs and their explicit knowledge of the properties and potentialities of modern materials. This combination of tacit knowledge of customer needs and explicit knowledge of technology was translated into their knowledgebased core competences in design and development, and became their earliest source of CA. These core competences combined with the attention gained from launching the company at the high profile US trials, led to rapidly growing sales among athletes.

The next stages in the development of Nike's knowledge-based competences were possibly fortuitous but were quickly followed by further organizational learning and the creation of new strategic knowledge. Many high profile American athletes adopted Nike's training shoes and the distinctive swoosh logo made the shoes instantly recognizable to television audiences watching their heroes perform. At the same time there were huge increases in the desire by young people to dress 
casually and a consequent expansion in this market in the 1970s and 1980s. Almost by chance, rather than by design, these young people began to copy their athletic heroes and wear Nike training shoes alongside the other casual items in their wardrobe.

Nike was very quick to learn from this development in the market for its products and adapt its strategy accordingly. Considerable attention was paid to understanding the psyche of young people in their teens and early 20s, which inevitably meant trying to gain insight into their thinking and the ways of behaving, which resulted from it. Clearly these young people admired successful athletes but, at the same time, Nike recognized that many young people go through a rebellious stage, particularly in their teens and early 20s. Their association was therefore more likely to be with athletes who were not only successful but who also displayed a rebellious streak. It was on the basis of this learning and knowledge that Nike took some of the key strategic decisions in terms of design and development, marketing, sponsorship and promotion and supply chain management which led to their global market leadership.

\section{Design and development}

In order to meet the needs and wants of its wider customer base of athletes and young fashion conscious people Nike took two key strategic decisions. The first was to extend its product range to cover an array of different sports, including some like soccer which did not have much of a following in the USA. The second was to extend the scope of its apparel range so that it was both suitable for competition and also for casual fashion wear. This demanded a broadening of Nike's knowledge base beyond footwear into the knowledge necessary to develop and market a full panoply of sports apparel and into the world of fashion. Design and development became key knowledge areas and were at the heart of their core competences and their growing competitive success. Central to these core competences was Nike's ability to combine knowledge of its customers with knowledge of the technology and materials used in the manufacture of footwear and sports clothing. A final ingredient was the ability of Nike's designers to match the fashion tastes of young people in the design of its products. Probably the most significant technological and design development was the invention of the 'Air' principle, based on a sole and heel which incorporated an air cushion. This was of benefit to athletes in absorbing the impact of their sport on their bodies but also became an iconic in a fashion sense among trendy young people.
The design and development process still takes place at Nike's headquarters in Portland, Oregon on the 75 acre World Campus, where there are some 2500 employees focussing on developing strategic product and customer knowledge.

\section{Marketing}

The other main strategic activities taking place at the World Campus are centred on developing marketing strategy based on explicit and tacit knowledge of customers. Nike's competitive success cannot be fully explained in terms of the excellence of its knowledge base relating to design and development. Marketing, promotion and brand name are as important to Nike's success as are product development and quality. Again Nike's knowledge of the psyche of its young customers is critically important when the company attempts to communicate with them and persuade them to buy its products. In order to promote its products Nike employs the services of athletes to endorse it products. These athletes are not only successful but are also stylish and are often controversial figures. As noted above, the controversial side of many of the athletes sponsored has appeal to the rebellious streak found in many young people. Examples of athletes sponsored by Nike over the years include Michael Jordan from basketball, John McEnroe and Andre Agassi from tennis, golf's Tiger Woods and soccer's David Beckham, Ronaldo and the Brazilian football team.

\section{Supply chain management}

Nike has also developed and embodied strategic knowledge throughout its value chain. This has involved strategic decisions in terms of which activities to conduct in-house, those to outsource to its suppliers, its logistics and relationships with customers and suppliers. The founders of Nike quickly realized that they did not have the necessary strategic knowledge of manufacturing to produce their own products. Engaging in this strategic learning enabled them to concentrate on key knowledge areas relating to design, development and marketing and, in addition, supply chain logistics, together with customer and supplier relationships.

Once a new product has been designed and developed in Portland, its manufacture is then outsourced to countries like Taiwan, China and Brazil. Nike imposes stringent quality control standards on its manufacturers. At the same time Nike is willing to share its knowledge of customers, 
technology and design with its suppliers to ensure the quality of their products.

Nike has built special relationships with the retailers who are permitted to sell its products. They are vetted for their financial security and for their expertise in relation to sportswear apparel. Retailers value Nike not only because its products are popular among consumers but also because of the service that Nike provides to them. Clearly it is important to retailers that they make an attractive return on the products that they sell. Nike supports its retailers by sharing its customer knowledge with them and by sharing a generous proportion of its premium price with them. This has the effect of encouraging retailers to promote Nike products over other brands. Retailers also benefit from Nike's association with top athletes and the large scale advertising campaigns, which promote their products.

Nike has also learned that it is critical to ensure that its products are available to retailers according to patterns of customer demand. As a consequence in Europe the company reduced the number of distribution warehouses from 32 to 5 , centred on its European headquarters in the Netherlands and main distribution warehouse in Belgium. This ensured greatly enhanced knowledge of patterns of demand for its products and, at the same time, more efficient and effective supply of its products to retail outlets.

Supply chain activities are also regarded as of importance in promoting the Nike brand. Nike has supported retailers who sell only its products, it has enabled some retailers to develop a Nike store within their store and more recently Nike has launched its own Nike Town Stores. The extension of Nike's customer and product base has encouraged Nike to deal as directly with customers as possible, both to protect the reputation of its brand, but, more importantly to allow it to learn from its customers, creating the new strategic knowledge which will serve as the basis of its future competitive edge.

The next section of the paper examines the reflexive loop of strategic learning, creativity and innovation as the co-ordinating and integrating mechanisms, which transform Nike's core competences into sustained and sustainable CA.

\section{STRATEGIC LEARNING AND KNOWLEDGE CREATION @ NIKE}

Innovation is viewed as being vital to Nike's continued success and this is reinforced by the rapid pace of change in the fashion and sports apparel industries. As a consequence there is a strong emphasis on strategic learning and the creation of strategic knowledge. Nike's leaders encourage its employees to think creatively and there is a strong but informal team-based work ethic. Informality is used as a mechanism for promoting forward thinking and the sharing of ideas, which are essential to the creation of new strategic knowledge. Design teams work in informal and picturesque surroundings to develop new concepts and products to keep the company in touch with its customers. Laboratories and test tracks to test out new products are also located on site.

Phil Knight believes that there are 7-year brand cycles in the industry and, in order to stay ahead, Nike spends enormous sums on continuous strategic knowledge development and innovation. As a consequence 'it is Nike's designs that are the most sought after by trainer connoisseurs' (The Independent newspaper, 25/06/1996).

Nike's swoosh logo is ranked alongside the red can of Coca Cola and the twin arches of McDonald's as the three most globally recognized logos. In fact, so well recognized was the logo that Nike sometimes uses its logo without the name itself. Today it is widely perceived as the most fashionable sports wear company in the world.

The massive growth of the scale and scope of Nike's activities has been accompanied by significant changes in the strategy and structure of the organization and in the way in which strategizing is conducted within the business.

Up until the early 1990s, the company was focused mainly on the domestic US market-with Nike Owned Companies and Distributor Agreements giving them presence in the rest of major developed countries of the world. These entities operated relatively autonomously with fairly basic reporting systems linking them through Regional Headquarters to their World HQ in Portland, Oregon. Consistency in Brand Marketing and Product development was heavily driven from the centre but the choice of systems; reporting and strategic direction were generally left in the hands of local country and Regional management teams.

One of the key challenges facing the Company was its ability to create; communicate and control the Corporate Strategic Plan throughout the Global organization - whilst at the same time allowing entities to remain locally relevant to individual market conditions in an organization operating in over 100 countries and administered through three regional Headquarters plus the USA domestic and Executive office. A further priority was to create an environment in which to release the power of 
middle management to communicate ideas in a 'bottom-up' approach-ultimately providing Executive Management with the ability to formulate a Strategic Plan, which effectively converted itself into a 'top down' directive.

The solution was found in four core elements encapsulated within a fairly rigid Process.

The Strategic Plan

The Business and Financial Plans

Performance Management

Business Review and eight quarter vision

The 'Process' - which was administered by a newly created Strategic Planning department was a key component to the success of the whole plan and was driven through timelines; consistency of definition; standardization of reporting formats and accuracy of both internal and external information.

The Strategic Plan itself is high level aspirational. The initial plan is created at Global Executive level-and incorporates some feedback from the Business review Process (to be described later). The initial plan was confidential and fairly generalistthe key components of which would be converted into Regional Strategic Plans-which would be locally relevant but at the same time emphasize and focus on priorities laid down in the Global Plan. The Plan was rolling in nature providing a 2-year vision-which was updated annually. The plan would be as valuable for its guidance on 'no go' areas as much as for its focus on future vision. For example, the feedback from the Business Reviews plus the implementation of 'Fields of Play' methodology contributed towards selecting those product and market opportunities that were no longer a priority within the strategy as well as identifying initiatives which must be pursued. The conversion of the Global guidelines into Regional Plans was crucial in reflecting individual Market maturity and opportunities. These regionally generated plans went through rigorous validation back to the global directional plan.

Business and Financial plans were driven off the Regional Strategic Plan and consist of detailed Functional Business Plans. Containing functional objectives; quarterly timelines and key metrics, these plans would be exchanged within the organization to ensure that all functions were aware of each others initiatives - allowing them to incorporate support-where necessary. This process was invaluable in ensuring communication and connectivity between functions. The content of the plans also formed the basis for creating staff workplans in support of the functional plan.
Performance Management was the third-essential element of the process and was supported by a comprehensive range of tools to measure both Financial and non-financial performance against pre-defined targets documented within the Business Plans. A complex range of micro reporting systems culminated in a concise and heavily focused Quarterly Scorecard review-which through its standardization and brevity allowed even the largest divisional reviews to be completed in hours rather than days. These Reviews - carried out by the Executive and Function Management teams-provided middle Managers with the opportunity to be exposed to the executive; as well as for Management to realign the business resulting from any slippage in performance. The meetings were very structured with keenly policed follow-up actions.

The Business Review was the final and vital part of the process. Known as the 'eight Quarter Forecast Review' it was a rolling activity (three times per year) which provided middle Management with the opportunity to project their vision of the business over a 2-year horizon. Again, it was prepared at country and divisional level to a standard global format. It was numerical - with a projection of sales and margins at a category level-but also allowed the opportunity for Managers to identify business opportunities as well as to give Consumer; Competitor and Marketing insights. This process-which after a series of Management reviews at Country and Regional level, would communicate to the Executive a 'bottom-up' view of the business going forward. This in turn-complemented by an Executive vision of the future-would act as both a source of information and influencer to the Executive in amending and formulating the new Global Strategic Plan for future years.

The next section broadens and enhances our conceptualization of the relationship between strategic learning, creativity and innovation as the basis of knowledge-based CA (Minocha and Stonehouse, 2006; Stonehouse et al., 2001) at Nike.

\section{STRATEGIC KNOWLEDGE, LEARNING AND CREATIVITY - THE INTERPLAY}

Having explored Nike's configuration and co-ordination of its strategic processes above, it becomes necessary to reflect on the nature of strategic knowledge, its treatment in the literature and more importantly our own understanding of it.

Organizations learn in order to create organizational knowledge. This organizational knowledge can be regarded as 'a shared collection of principles, 
facts, skills and rules which inform organizational decision-making, behaviour and actions' (Stonehouse and Pemberton, 1999). Strategic knowledge, however, is the basis of an organization's core competences and CA and arises not from organizational learning alone but from the creative use of that knowledge in developing and implementing the strategy of the organization (Minocha and Stonehouse, 2006).

Strategic knowledge can be regarded as a unique combination of explicit and implicit knowledge. Whereas explicit knowledge is knowledge which has a clearly stated meaning and can be recorded, stored and readily communicated from one person to another, tacit (or implicit) knowledge is inferred or implied, often unstated, based upon individual experience and is difficult to record, store and communicate (Demarest, 1997; Stonehouse and Pemberton, 1999). Both forms of knowledge begin as individual knowledge but, to substantially improve performance, they must be transformed into organizational knowledge. Nonaka et al. (2000) point out the importance of combining explicit and tacit knowledge to create new strategic knowledge as a source of CA.

Knowledge can also be regarded as specific or generic. Generic knowledge can be of value in a range of businesses and business activities while specific knowledge is particular to a particular area of business, market or industry sector. Whilst generic knowledge is necessary to successful operation specific knowledge is more likely to form the basis of core competences and, hence, superior performance. For example, Stonehouse and Pemberton (1999) cite the example of Porsche's specific knowledge of automotive design and engineering technology as being at the heart of its core competences.

In short, CA arises from some unique combination of tacit, explicit, specific and generic knowledge forged together into strategic knowledge and expressed through core competences. Such knowledge can relate to any or all of an organization's value adding activities including research, design and development, technology, logistics and supply chain, manufacturing and operations, sales and marketing and so on. It can, and usually does, also relate to an organization's knowledge of, and relationships with, its stakeholders whether customers, suppliers, shareholders or employees. Probably the most important strategic knowledge relates to customers and their wants but it is the ability to translate this knowledge into new integrated knowledge which transforms sales, marketing, supply chain management and operations that gives CA as illustrated by the Nike example above.
To put it another way, knowledge relating to one area of the value chain or one set of stakeholders is unlikely to be of sufficient strategic value to give an organization CA. It is the combination and integration of knowledge relating to customers and their wants, other stakeholders and several areas of the value chain, which produces strategic knowledge and CA. Such knowledge, and its application, will transform value chain activities and relationships with stakeholders.

Thus, in our usage of the term strategic knowledge we refer to 'knowledge which leads to the creation and development of knowledge-based core competences which distinguish organizations from their competitors and allow them to outperform them' (Stonehouse and Pemberton, 1999 in Minocha and Stonehouse, 2006). Such knowledge arises from organizational learning and the closely related processes of knowledge creation and application. The social architecture of an organization, in terms of its leadership, culture structure and infrastructure is critical to its ability to learn, create and apply knowledge strategically (Nonaka et al., 2000; Senge, 1990; Stonehouse and Pemberton, 1999). Quinn (1992) emphasizes the importance of social architecture in accelerating the processes of learning, knowledge creation and application stating that 'another unique characteristic of knowledge is that it is one of the few assets that grows most-usually exponentially-when shared'. The production of strategic knowledge is thus dependent upon what Argyris (1991, 1999) and Argyris and Schon (1978, 1996) call 'double loop learning' and what Senge (1990) calls 'generative learning'. Argyris and Schon argue that learning must be critical and reflective so that 'new knowledge and principles are determined which improve both the rate learning and the performance of the organization' (Minocha and Stonehouse, 2006). It is the reflective element of strategic learning which develops new knowledge and, potentially, CA. The increasingly competitive and rapidly changing business environment means that the only way to sustain exceptional performance is through continuous and reflective strategic learning (Minocha and Stonehouse, 2006).

Equally, the pace of change (Petersen et al., 2004) in business requires a focus on improving the learning and creative processes in an organization by learning about learning itself (Argyris and Schon, 1996; Bateson, 1972; Pemberton and Stonehouse, 2000). Through learning about an organization can transform its social architecture into one, which dramatically improves the rate at which it learns and creates new knowledge (Aksu and Bahattin, 2005; Bell and Bell, 2005; Bogenreider, 2002; Gigerenzer, 2006; Hampden-Turner and 
Trompenaars, 2006; Hines et al., 2004; Karkkainen and Hallikas, 2006; Perrott, 2004).

It is also important to emphasize the importance of creativity and innovation in the development of strategic knowledge. The creation of new knowledge does not necessarily result in innovation according to the research literature (Quintas and Brauner, 1999). It involves 'the exploitation of new or existing knowledge in new contexts' (Quintas and Brauner, 1999: 16). Lundvall (1992) proposes that learning and innovation are linked and that learning provides incremental additions to a store of knowledge constructed through practice and experience. Thus, innovation involves the creation of knowledge as well as the application of existing knowledge against social processes in evolving organizational cultures (Murray and Blackman, 2006; Zairi and Al-Mashari, 2005). Organizational learning alone is a necessary but insufficient condition for the production of strategic knowledge. A further dimension of creativity and innovation is required (Nonaka, 1991; Nonaka and Takeuchi, 1995; Prigogine, 1980) in addition to the perspective provided through the lens of organizational learning.

This paper has thus far explored the sources of strategic knowledge and its creation through the case study of Nike. Having critiqued the literature we reflect on the practices at Nike to derive lessons for future reflective practice in KM.

\section{KNOWLEDGE PROCESSES@ NIKE- LESSONS FOR THE FUTURE}

There are a number of lessons to be learned from the case study of Nike specifically in terms of the strategic knowledge employed by Nike in building the core competences which allow the company to outperform its competitors and the ways in which the knowledge is created and deployed within and outside the organization. The preceding discussion identifies the key areas of strategic knowledge, which deliver its exceptional performance. The knowledge areas relate to customers and their buying behaviour, product design and development, marketing, supply chain management. Each of these knowledge areas is a highly complex combination of tacit and explicit knowledge relating to customers, design, marketing and supply chain management (Nonaka et al., 2000) which is extremely difficult for competitors to emulate. Even more important, however, is the way in which these knowledge areas are integrated together to form the company's core competences (Pemberton and Stonehouse, 2000; Stonehouse and Pemberton,
1999), which differentiate Nike from its competitors, providing a source of sustainable CA. Also key to Nike's strategic knowledge is its understanding of the tacit knowledge which influences the thinking and buyer behaviour of its main customer groups and, in turn, is exploited in design and product development and in marketing strategies. This is further incorporated into its supply chain management where retailers benefit from Nike's marketing, pricing strategy and highly efficient supply chain. Potential emulation by competitors of each of these individual areas of strategic knowledge is rendered difficult by the combination and integration of the knowledge areas throughout the company's entire value system.

Organizational learning and knowledge creation are just as important to Nike's CA in that they ensure its sustainability (Senge, 1990). There is considerable evidence of Nike's continuous learning in creativity from its rapidly changing product range, to its innovative advertising campaigns and the improvements in its supply chain management. This is double-loop or generative learning (Argyris, 1977, 1991, 1999; Argyris and Schon, 1996; Senge, 1990). Nike's social architecture is an indication of its 'learning about learning' (Argyris and Schon, 1996; Bateson, 1972; Pemberton and Stonehouse, 2000). Leadership provides a clear vision, which permeates the whole organization, it encourages and supports development of its employees and promotes a culture within which creativity and sharing of ideas are encouraged (Nonaka et al., 2000; Senge, 1990; Stonehouse and Pemberton, 1999).

\section{CONCLUSIONS}

The Nike case study provides significant new insight into the role of strategic learning and creativity in developing the strategic knowledgebased core competences, which produce sustained superior performance, which has only been covered superficially in the literature to date. The integration of its customer, design, marketing and supply chain knowledge generate a strategy, which is effective, complex and difficult for competitors to emulate. This strategic knowledge is constantly replenished through strategic learning and creativity, which is facilitated by Nike's social architecture, which provides clarity of purpose and an environment, which promotes the development and sharing of innovative new ideas. Whilst CA can never be completely assured Nike's approach to knowledge, its creation and incorporation into core competences most certainly increases the chances of sustaining superior performance. This opens up avenues for 
future research into the integration of strategic KM processes, which differentiate Nike from less successful organizations within which knowledge management remains a set of fragmented systems and procedures.

\section{REFERENCES}

Aksu A, Bahattin Ö. 2005. Individual learning and organization culture in learning organizations: five star hotels in Antalya region of Turkey. Managerial Auditing Journal 20(4): 422-441.

Argyris C. 1977. Double loop learning in organizations. Harvard Business Review 55(5): 115-125.

Argyris C. 1991. Teaching smart people how to learn. Harvard Business Review 69(3): 99-109.

Argyris C. 1999. On Organizational Learning. Blackwell Publishers Ltd.: Oxford.

Argyris C, Schon D. 1978. Organizational Learning: A Theory of Action Perspective. Addison-Wesley: Reading, MA.

Argyris C, Schon D. 1996. Organizational Learning II. Addison-Wesley: Reading, MA.

Bateson G. 1972. Steps to an Ecology of Mind. Chandler Publishing Co.: San Francisco.

Bell M, Bell W. 2005. It's installed... now get on with it! Looking beyond the software to the cultural change. British Journal of Education Technology 36(4): 643656.

Bogenreider I. 2002. Social architecture as a prerequisite for organizational learning. Management Learning 33(2): 197-212.

Demarest M. 1997. Understanding knowledge management. Long Range Planning 30(3): 374-384.

Gigerenzer G. 2006. Follow the leader. Harvard Business Review 84(2): 58-59.

Hampden-Turner C, Trompenaars F. 2006. Cultural intelligence: is such a capacity credible? Group $\mathcal{E}$ Organization Management 31(1): 56-63.

Hines P, Holwe M, Rich N. 2004. Learning to evolve-a review of contemporary lean thinking. International Journal of Operations and Productions Management 24(9-10): 994-1011.

Karkkainen H, Hallikas J. 2006. Decision making in interorganizational relationships: implications from systems thinking. International Journal of Technology Management 33(2): 144-160.

Kiraka R, Manning K. 2005. Managing organisations through a process-based perspective: its challenges and benefits. Knowledge and Process Management 12(4): 288-298.
Lundvall BA. 1992. National Systems of Innovation: Towards a Theory of Innovation and Interactive Learning. Pinter Publishers: London.

Minocha S, Stonehouse G. 2006. The learning trap: a bollywood frame for strategic learning. Management Decision 44(10): 1344-1362.

Murray P, Blackman D. 2006. Managing innovation through social architecture, learning, and competencies: a new conceptual approach. Knowledge and Process Management 13(3): 132-143.

Nonaka I. 1991. The knowledge-creating company. Harvard Business Review 69(6): 96-104.

Nonaka I, Takeuchi H. 1995. Knowledge-Creating Company: How Japanese Companies Create the Dynamics of Innovation. Oxford University Press: Oxford.

Nonaka I, Toyama R, Konno N. 2000. SECI, BA and leadership: a unified model of dynamic knowledge creation. Long Range Planning 33(1): 5-34.

Pemberton J, Stonehouse GH. 2000. Organizational learning and knowledge assets-an essential partnership. The Learning Organization 7(4): 184-193.

Perrott BE. 2004. Learning for the networked economy: A role for simulation for EISTA 04. Eista '04: International Conference on Education and Information Systems: Technologies and Applications. Vol 2, Proceedings, 407-411.

Petersen A, Boer H, Gertsen F. 2004. Learning in different modes: the interaction between incremental and radical change. Knowledge and Process Management 11(4): 228-238.

Prigogine I. 1980. From Being to Becoming: Time and Complexity in the Physical Sciences. W.H. Freeman: San Francisco.

Quinn JB. 1992. Intelligent Enterprise: A knowledge and Service Based Paradigm for Industry. The Free Press: New York.

Quintas P, Brauner EJ. 1999. Managing Knowledge and Innovation, B823, Unit 8, The Open University.

Senge P. 1990. The Fifth Discipline: The Art and Practice of the Learning Organization. Doubleday: New York.

Stonehouse GH, Pemberton J. 1999. Learning and knowledge management in the intelligent organization. Participation and Empowerment: An International Journal 7(5): 131-144.

Stonehouse GH, Pemberton JD, Barber CE. 2001. The role of knowledge facilitators and inhibitors: lessons from airline reservations systems. Long Range Planning 34(2): 115-138.

Stonehouse GH, Hamill J, Campbell D, Purdie A. 2003. Global and Transnational Business: Strategy and Management. Wiley: London.

Zairi M, Al-Mashari M. 2005. Developing a sustainable culture of innovation management: a prescriptive approach. Knowledge and Process Management 12(3): 190-202. 
Copyright of Knowledge \& Process Management is the property of John Wiley \& Sons. Inc. I Business and its content may not be copied or emailed to multiple sites or posted to a listserv without the copyright holder's express written permission. However, users may print, download, or email articles for individual use. 